\title{
PROJETO DE PRODUTO SIMBÓLICO DA CULTURA CABOCLA DA REGIÃO OESTE DE SANTA CATARINA
}

SYMBOLIC PRODUCT DESIGN OF THE CABOCLO'S CULTURE OF THE WEST REGION OF SANTA CATARINA

\section{Alexandre Junior Favaretto (UNOCHAPECÓ) \\ Rachel Corrêa de Quadros, M.Sc.(UNOCHAPECÓ) Henrique Telles Neto, M.Sc. (UNOCHAPECÓ)}

\section{Palavras Chave}

Cultura Cabocla; Design de Raiz; Valores Simbólicos

\section{Key Words}

Caboclo Culture; Root Design; Symbolic Values

\section{RESUMO}

O presente artigo faz parte de um projeto de pesquisa, na qual realizou-se um resgate histórico sobre o caboclo da região oeste de Santa Catarina, por meio de pesquisas qualitativas e análises comparativas, relacionando design e cultura cabocla, a fim de compreender fatores como: a importância das funções de produto como mantenedora da cultura cabocla na região estudada, projeto de produto, identidade cultural e o valor simbólico dos produtos artesanais produzidos pelos caboclos. Como conclusão deste estudo, projetou-se a reprodução fiel de um produto de design de fator simbólico a partir das pesquisas realizadas nos artigos anteriores, mostrando que é possível inovar no planejamento de novos produtos sem perder a cultura e as raízes do caboclo.

\section{ABSTRACT}

This article is part of graduation's reasearch project about the historical background of the caboclo in the western region of Santa Catarina. The work took place through qualitative research and comparative analysis, relating design and the caboclo culture in order to understand factors such as: the importance of product functions as a retainer of caboclo culture in the studied region, product design, cultural identity and the symbolic value of the craft products produced by the caboclos. As a conclusion of this line of research, it was designed a faithful reproduction of a product of symbolic meaning, carried over from the previous research articles, showing that it is possible to innovate in designing new products without losing the culture and the roots of the caboclo. 


\section{INTRODUÇÃO}

Uma cultura rica em valores passados de geração para geração, que marcam e identificam pessoas fortes e batalhadoras. De vida marcante e admirável, os caboclos da região oeste de Santa Catarina destacam-se principalmente por seu modo de vida "simples", casas de pau a pique, chão batido, criação de animais, plantio, trabalho braçal, seu valor e importância no ciclo da erva-mate e na extração da madeira.

"Caboclo" é um termo empregado para definir, entre outras coisas, os indivíduos e as culturas que se originaram a partir da miscigenação entre indígenas e europeus, que no território brasileiro teve início após a chegada dos portugueses, ou "lusitanos". Neste sentido, corresponde ao termo luso-brasileiro, que expressa esta dualidade étnica e cultural. (ONGHERO, 2012, p. 33).

O presente artigo tem como objetivo apresentar por meio do projeto de um produto simbólico os resultados obtidos a partir de pesquisas e estudos realizados sobre a cultura cabocla da região Oeste de Santa Catarina e sua relação com o design.

Projetar é fácil quando se sabe como fazer. Tudo se torna fácil quando se conhece o modo de proceder para alcançar a solução de algum problema, e os problemas com que deparamos na vida são infinitos: problemas simples que parecem difíceis porque não se conhecem e problemas que parecem impossíveis de resolver. (MUNARI, 1998, p. 2)

A pesquisa realizada para o desenvolvimento deste artigo foi qualitativa, a qual reuniu ao longo de um ano e meio resgates históricos da cultura cabocla da região oeste de Santa Catarina. Foram coletadas informações sobre a cultura e o modo de vida dos caboclos, seus costumes e crenças.

Frente às pesquisas realizadas foram abordados temas como projeto de produto, funções de produto, o caboclo do oeste de Santa Catarina, o valor simbólico dos produtos artesanais da cultura cabocla, pesquisa aplicada, análise comparativa das funções dos objetos, cultura cabocla do oeste catarinense, cultura contemporânea, identidades culturais, design e cultura material, o trabalho caboclo, a extração da erva-mate, a ergonomia nas ferramentas de trabalho e apresentação de análise de artefato caboclo, o "borraio".
"Design, arte e artesanato têm muito em comum e hoje, quando o design já atingiu uma certa maturidade institucional, muitos designers começam a perceber o valor de resgatar as antigas relações com o fazer manual." (CARDOSO, 2000, p. 17). Assim, ao longo de toda pesquisa buscou-se entender onde está o papel do designer como profissional que vislumbra ideias inovadoras sem perder o valor histórico e simbólico do artefato. Para o desenvolvimento deste artigo foram resgatados alguns assuntos teóricos visando embasar o desenvolvimento de um projeto de produto simbólico, bem como sua marca, inspirados em um objeto de uso cotidiano de caboclos utilizado para suprir suas necessidades. Por tratar da cultura local este artigo se faz de grande valor e importância para a história cultural da região oeste de Santa Catarina.

\section{PROJETO DE PRODUTO}

"O Método de projeto, para designers, não é absoluto nem definitivo; pode ser modificado caso ele encontre outros valores objetivos que melhorem o processo. $E$ isso tem a ver com a criatividade do projetista, que ao aplicar o método, pode descobrir algo que o melhore." (MUNARI, 1998, p. 11). Expressar uma ideia, sentimentos e emoções através de um objeto é um dos maiores desafios de um designer, cabe a ele ter um certo domínio em outras áreas de estudo, como antropologia e psicologia, a fim de compreender sobre as peculiariedades das diferentes formas de comportamento de indivíduos de culturas diferentes, por exemplo.

"No design de produto mais tradicional, as funções de um produto freqüentemente parecem estar dadas. Uma cadeira serve para sentar-se, um carro, para deslocar-se de um ponto a outro, e um telefone permite falar com pessoas que não estão presentes." (BONSIEPE, 2015, p. 53). Conseguir transmitir uma ideia para um produto é o que torna valorizado o produto final. Este aspecto é de extrema importância assim como saber definir as funções que serão agregadas ao produto, definindo bem seu público alvo e as características que se deseja transmitir ao usuário. "A criatividade é o coração do design, em todos os estágios do projeto. O projeto mais excitante e desafiador é aquele que exige inovação de fato." (BAXTER, 1998, p. 51).

Ao lançar novo produto no mercado, deve-se estabelecer metas, verificar se satisfaz aos objetivos propostos, se é bem aceito pelos consumidores, e se o projeto pode ser fabricado a um custo aceitável, considerando a vida útil do produto no mercado. Os métodos de inovação 
devem considerar todos esses fatores e minimizar os riscos de fracasso do novo produto. (BAXTER, 1998, p. 2).

"Toda a cultura de massa-midiática tornou-se uma formidável máquina comandada pela lei da renovação acelerada, do sucesso efêmero, da sedução, da diferença marginal." (LIPOVETSKY, 2002, p. 205). O papel do designer em projeto de produto pode ir além do simples fator inovação, buscando resolver problemas sociais, contribuindo para o desenvolvimento do país, levando em considerações fatores como moral e ética.

Segundo Baxter (1998, p. 231) sobre configuração e projeto de produto: "A configuração do projeto começa com conceitos escolhidos e termina com o protótipo completamente desenvolvido e testado".As quatro fases que a configuração de um projeto compreendem:

Geração de ideias, explorando-se todas as formas possíveis de fabricar o produto. Seleção das ideias, escoIhendo-se a melhor ideia, em comparação com as especificações de projeto. Análise das possibilidades de falhas e seus efeitos, para levantar os possíveis pontos de falha do produto. Construção e teste do protótipo, para aprovar ou rejeitar o projeto. (BAXTER, 1998, p.231).

“O planejamento do produto inclui: identificação de uma oportunidade, pesquisa de marketing, análise dos produtos concorrentes, proposta de novo produto, a elaboração da especificação e da oportunidade e a especificação do projeto". (BAXTER, 1998, p. 122). É possível que na fase de desenvolvimento do projeto de um produto as fases que o configuram não se desenvolvam em ordem, muitas vezes sendo necessário avançar ou retroceder algumas etapas a fim de testar a qualidade da ideia desenvolvida, assim possibilitando o desenvolvimento até chegar no produto final.

"Na configuração do produto se mostram os atributos que constituem a sua possibilidade de comunicação, a sua "cara". O produto diz de si próprio: suas qualidades e características, o seu modo de produção, o que serve para quem se dirige." (NIEMEYER, 2007, p. 21). Um bom produto de design pode ser desenvolvido pensando diretamente no público alvo, ou seja, no consumidor final, então, é necessário que no planejamento sejam estudados os perfis de usuários a quem o produto se destina, analisando quais são as necessidades deste usuário, suas afinidades e o que ele busca.

A existência de um produto decorre da possibilidade de abordagem de um problema, dos meios disponíveis, das restrições presentes e das metas visadas. O designer, com sua competência, seus valores e suas possibilidades, atua como articulador com o setor produtivo em que atua, tomador de seu serviço. Assim, da ligação do designer com o setor produtivo no qual trabalha resulta a solução projetual. (NIEMEYER, 2007, p. 21).

"O planejamento de um produto é uma das atividades mais difíceis do desenvolvimento de um produto. Pode ser frustrante a sensação de estar pulando no vazio, quando se procura especificar um produto, cujo desenvolvimento ainda não foi iniciado". (BAXTER, 1998, p. 122). Qual é o diferencial do produto a ser desenvolvido, como ele vai transmitir suas funções para o consumidor, atraindo-o. Esses são alguns fatores que devem ser pensado no planejamento de um produto. Deve-se pensar como um determinado produto vai atrair consumidores específicos por exemplo.

\begin{abstract}
A seleção inicial do melhor conceito envolve primeiro penar em todos os princípios de operação para o produto e, depois, a seleção do melhor deles, baseando-se nas especificações do projeto. No estágio final do desenvolvimento, para a seleção da melhor configuração para o projeto é necessário pensar, primeiro, em todas as formas possíveis de fabricação do produto e, em segundo lugar, fazer a seleção da melhor configuração, baseando-se nas especificações do projeto. Assim, esse ciclo se repete ao longo de todo o processo de desenvolvimento de novos produtos, operando em fronteiras cada vez mais fechadas, determinadas pelas etapas precedentes, até se chegar em uma ou duas alternativas finais de projeto. (BAXTER, 1998, p. 20).
\end{abstract}

"Quando todo o ciclo de vida do produto está incluído na sua dimensão pragmática, ela compreende o conhecimento sobre o designer, o fabricante, o marketing, as vendas, os compradores, o consumo, a legislação, a história." (NIEMEYER, 2007, p. 52). Para um projeto de produto ser considerado "bom", é necessário que se pense em estabelecer certa harmonia em seu planejamento, garantindo que o produto final, ao chegar ao consumidor seja bem aceito.

O ciclo de vida dos produtos forma um ciclo fechado: as matérias-primas são retiradas da natureza e, ao final da vida do produto, retornam a 
ela - a terra é uma fonte limitada de matérias-primas. Os fabricantes devem compreender que, por causa disso, os produtos devem ser reciclados e reutilizados. (CARPES, 2014, p. 181).

Dentro da metodologia de planejamento, há a necessidade de reflexão diante das diversas relações cabíveis entre design, produto e consumidor. $\mathrm{O}$ fator sustentabilidade tão em alta no mercado do design, busca inovar e capacitar profissionais capazes de pensar no desenvolvimento de produtos pensando em suas contribuições para o desenvolvimento de um pais, considerando qualidades positivas e negativas de um produto a pequeno, médio e longo prazo, buscando para a produção matérias primas renováveis que não agridam ao meio ambiente.

A humanidade vive em um ambiente com recursos limitados, e a produção industrial embora essencial para manutenção da vida moderna - é a principal fonte de problemas ambientais, gerando poluição, desmatamento, aquecimento global e extinção de espécies. Por esse motivo, a necessidade de recomendações ecológicas na fabricação de produtos é cada vez maior, e uma regra vital para os projetos. (CARPES, 2014, p. 177).

“Um produto é formado pela reunião de vários elementos: materiais, dimensões, proporção, pelas partes que o compõem, pela organização das suas partes, cores, acabamento etc." (NIEMEYER, 2007 , p. 34). Quando pensamos em projeto de produto ligado a uma determinada cultura, se faz necessário conhecer o passado e as raízes das pessoas pertencentes a ela. $O$ fator inovação parece destacar-se no campo de projeto de produto, pois cada vez mais designers aparentam buscar e desenvolver novos conceitos e estilos. Ser destaque em um mercado em constantes evolução, muitas vezes parece ser algo muito distantes, fora de mão, mas deve-se acreditar que nada é impossível. Analisar a forma como um produto será utilizado e visto por seus usuários, é um fator muito importante.

Com a evolução do design e a ampliação de seu papel, o seu caráter estratégico adquire crescente força. Além do papel do design na manutenção da produção e da circulação de produtos e serviços - o seu vetor econômico - é relevante a sua contribuição na elevação da qualidade de vida individual e social: o vetor social do design. Assim, os designers devem estar atentos à relação comunicativa estabelecida entre produto e o seu destinatário. (NIMEYER, 2007, p. 22).

Da mesma maneira que se faz importante a ideia inovadora para o desenvolvimento de um produto de design que se destaque no mercado, também é comprovada a importância da ergonomia. Assim sendo de extrema importância para que um produto se torne funcional, prático e de qualidade estética.

A ergonomia busca a redução das exigências biomecânicas, diminuição das chances de erros na operação de produtos, boa postura física, adequada percepção de informações e boa interface do produto - de forma que os objetos, mostradores ou controles estejam dentro do alcance dos movimentos corporais. (CARPES, 2014, p. 160).

Ainda sobre a ergonomia:

A ergonomia é a ciência que estuda as maneiras de melhorar as condições dos trabalhadores no local de trabalho. Vale-se das contribuições advindas do conhecimento da anatomia humana, da fisiologia e da medicina do trabalho. Muitas pesquisas e aplicações práticas são realizadas em vários setores: nos transportes públicos e nos lugares de condução e comando de qualquer veículo a fim de melhores as condições de segurança e reduzir acidentes; nos postos de trabalho, nos escritórios e nas grandes lojas; no setor urbanístico, com particular atenção para o caso dos deficientes físicos; nos ambientes onde há muito ruído, ou temperaturas abaixo ou acima do normal, ou em que se trabalha em condições de luz impróprias. (MUNARI, 1998, p. 342).

No processo de criação de um produto existe a necessidade de se levantar algumas questões que influenciarão diretamente no planejamento de um produto, dentre elas as que mais se destacam são as que fazem relação com o usuário final.

A atividade de desenvolvimento de um novo produto, não é tarefa simples. Ela requer 
pesquisa, planejamento cuidadoso, controle meticuloso e, mais importante, o usos de métodos sistemáticos. Os métodos sistemáticos de projeto exigem uma abordagem interdisciplinar, abrangendo métodos de marketing, engenharia de métodos e a aplicação de conhecimento sobre estética e estilo. Esse casamento entre ciências sociais, tecnologia e arte aplicada nunca é uma tarefa fácil, mas a necessidade de inovação exige que ela seja tentada. (BAXTER, 1998, p. 3).

Através do estudo da ergonomia é possível compreender a forma com que o usuário ira interagir com o produto, assim sendo possível pensar em questões como peso do produto, tamanho e forma, dentre tantas outras. Um produto ergonômico significa que este foi desenvolvido perante várias análises para que o resultado final seja o máximo agradável e funcional, transmitindo conforto, segurança e praticidade. Desde o tempo dos primeiros artesões se buscava compreender os usuários, para a criação de um produto.

Os melhores designers do futuro serão multifuncionais e se sentirão à vontade discutindo pesquisa de mercado, fazendo um rendering a cores de um novo produto ou selecionando o tipo de material que deve ser usado no produto, o mais importante é ter conhecimentos básicos e metodológicos para o desenvolvimento de novos produtos, para coordenar as atividades do projeto. (BAXTER, 1998, p. 3).

“O artesão nem sempre examinava racionalmente os detalhes do objeto de uso que produzia. Por isto tinha liberdade para a introdução de variações e de formas novas." (LÖBACH, 2001, p. 37). Até a Revolução Industrial no século XIX, objetos de uso cotidiano eram fabricados de maneira artesanal, feitos a mão, possuíam como principal característica a função a que foram destinados, para o que e de qual forma seriam utilizados.

“Todas as épocas foram marcadas por novos materiais e tecnologias: ferro fundido, aço ou concreto não eram mais processados em pequenos estabelecimentos ou manufaturas por trabalhadores manuais." (BÜRDEK, 2010, p. 21). Após a Revolução, houveram grandes modificações na forma de se produzir objetos. Muitos objetos passaram a ser produzidos de forma industrial, grande parte dos artesões da época perderam seus postos de trabaIho, sendo então substituídos por "grandes" máquinas inovadoras para a época, as quais simbolizavam uma revolução tecnológica no campo da produção, onde passaram a realizar as mesmas tarefas dos artesões, mas com mais agilidade, em maiores quantidades e diminuindo os gastos com empregados.

Da necessidade surge a criação e a adaptação. Possuir a visão e a capacidade de planejar produtos de modo que venham facilitar a vida no cotidiano é um assunto que desperta interesse e que vem sendo estudado desde muito tempo.

Objetos e utensílios caboclos ainda podem ser encontrados hoje, em versões mais modernas e contemporânea, que passaram a ser produzidas em escala de forma industrial, após a Revolução Industrial.

(...) indivíduos de culturas distintas são identificados por características como hábitos de alimentação, comportamento, vestuário, entre outros que se manifestam em meio a contornos que possibilitam a descrição de traços fundamentais. Todavia, como as sociedades são dinâmicas e se relacionam umas com as outras, influenciam-se de modo mútuo, configurando o fenômeno de difusão, vinculado à tradição uma territorialidade. (ONO, 2006 apud LORENZI, MORGENSTERN \& CIPINUK, 2015, p. 31).

O trabalho do profissional de design voltado para as funções de produto no desenvolvimento de objetos que resgatem uma determinada cultura, como objetos, artefatos e ferramentas por exemplo, pode ser considerado como desenvolvedor de produtos culturais.

\section{PRODUTO SIMBÓLICO}

Para Carpes (2014, p. 185), "A função global é aquilo que o produto faz ou realiza para justificar a sua existência ou ainda, é a função necessária para que o produto realize a tarefa estabelecida." Todo produto é desenvolvido para alguma finalidade, e estas são estabelecidas pelas funções de produto. No desenvolvimento de um projeto de produto é papel do designer estudar e verificar quais funções se adaptam melhor ao perfil do usuário, afim de suprir suas necessidades, é então necessário que o designer conheça e compreenda o seu público alvo a fim de estabelecer quais funções devem ser utilizadas em cada caso. Através do estudo do público alvo ao qual um produto se destina, é possível compreender as necessidades reais do usuário, e de que forma essas necessidades podem ser supridas através de um produto. 
"A semiótica aplicada ao projeto introduz aportes para resolver as questões decorrentes da preocupação da comunicação do produto do design." (NIEMEYER, 2007, p. 22). Ter o conhecimento e um estudo sobre o público-alvo e mercado, faz com que sejam menores as chances de um produto não ser bem aceito quando lançado no mercado.

Dependendo da cultura, um signo ou uma articulação sígnica é interpretada de modo próprio. Para o adequado desenvolvimento do projeto, o designer deve ter familiaridade, compreensão e domínio do grupo cultural em que o produto resultante circulará. Aspectos quanto a tradições, costumes, valores, religião, características políticas e econômicas devem ser mapeadas na fase inicial do projeto para evitar perda de tempo em futuros ajustes ou, o que é pior, fracasso da solução adotada. (NIEMEYER, 2007, p. 22).

Sobre as funções de produto, aplicadas no design industrial, o designer Löbach (2001, p. 55) afirma:

No processo de utilização se satisfazem as necessidades do usuário, dotando-se o produto de certas funções. No processo de configuração de produtos industriais, o projetista e o designer industrial devem otimizar as funções de um produto visando satisfazer às necessidades dos futuros usuários. Daí, se entender que o designer industrial deve conhecer as múltiplas necessidades e aspirações dos usuários e grupos de usuários, de forma a poder dotar o produto com as funções adequadas a cada caso.

“Um objeto tem função simbólica quando a espiritualidade do homem é estimulada pela percepção deste objeto, ao estabelecer ligações com suas experiências e sensações anteriores." (LÖBACH, 2001, p. 64). A função simbólica diz respeito as diferentes formas que o usuário interage em sociedade, leva em conta diversos fatores, remetendo o usuário a diferentes sensações já vividas. Sobre o processo de definição de funções:

Quando um designer industrial projeta produtos industriais, determina a função do produto. Isto acontece no trabalho em colaboração com o projetista, segundo um princípio de divisão de tarefas. Em muitos casos o projetista se encarrega das funções práticas dos produtos, ocupando-se o designer das funções estética e simbólica. Esta divisão de funções dos produtos só será frutífera se as diferentes atividades forem coordenadas com vistas ao resultado global. (LÖBACH, 2001, p. 55).

“Um produto pode ter muitas funções e propósitos. Esta multiplicidade não impede que alguém defina a principal função para a qual um objeto foi projetado." (NIEMEYER, 2007, p. 52). Dar a preferência a uma determinada função, é uma forma de distinguir um produto de outros. As três funções também podem ser aplicadas em um mesmo produto, mas dando preferência e ressaltando apenas uma delas de forma individual e marcante, é uma forma de mostrar com clareza a qual público determinado produto se destina.

“Na produção manual os produtos eram fabricados para um reduzido número de clientes, atendendo as expectativas e aos desejos individuais desse clientes." (LÖBACH, 2001, p. 37). O grande marco das transformações no campo de projeto de produto se deu no momento da Revolução Industrial onde os pequenos e simples utensílios antes desenvolvido por artesões perante as necessidades do cotidiano, objetos que possuíam como principal característica a função prática passaram a ser produzidos industrialmente e em escala, substituindo o trabalho manual dos artesãos.

Levando em conta não apenas a necessidade fisiológica dentre as necessidades básicas do ser humano. É perceptível e cabível de compreender que a função prática é uma das mais importantes, e uma das que se deve deter maior atenção no planejamento de um produto, porém, em um mundo de constantes transformações onde se dá grande valor às inovações, há a necessidade de agradar as pessoas em todos os sentidos, neste momento se apresentam importantes todas as funções de produto. As pessoas estão mais interessadas muitas vezes no aspecto visual do que no funcional. Em um mundo onde o capitalismo cresce de maneira desenfreada, cabe ao designer desenvolver a inovação pensando no diferencial, sendo capaz de criar e projetar o futuro.

“No atual sistema econômico, denominado capitalismo, quanto menor a escala de produção, tendo às peças únicas ou exclusivas, maior seu valor econômico, e este eleva-se quanto mais alto for o valor cultural do produto." (LORENZI, MORGENSTERN, CIPINIUK, 2015, p. 29). Representando os valores de um povo, o artesanato construiu valores que podem transmitir sentimentos, crenças, religiões, costumes, entre outros. Os artefatos que representam a cultura 
cabocla, feitos por artesões, contam histórias de vida dessas pessoas. As peças desenvolvidas pelos artesões se diferenciavam uma das outras, por se tratar de um trabalho manual, cada peça apresentava seu diferencial, desta forma é possível compreender a questão de valores, quando se trata de peça única feita a mão.

Figura 01: Sra. Otilia Siqueira com uma peneira

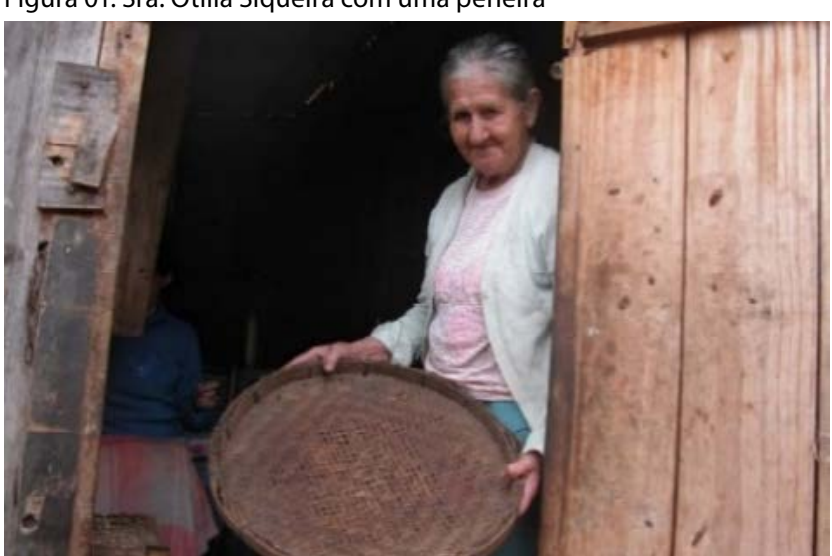

Fonte: Acervo CEOM - UNOCHAPECÓ (2015)

Desenvolvidos à partir das matérias-primas disponíveis, os primeiros artefatos artesanais dos caboclos, baseavam-se em suas necessidades.

Os artefatos artesanais parecem ser mais significativos em termos culturais, daí se considera que possuem maior valor agregado, o que do ponto de vista prático poderia justificar a sua permanência e os preços que são cobrados, haja vista suas aproximações de supostas essências universais e invariáveis da cultura. (LORENZI, MORGENSTERN, CIPINIUK, 2015, p. 29).

A partir do estudo e compreensão da cultura cabocla é possível compreender o valor contido nestes artefatos. Conhecer a história deste povo, facilita o entendimento acerca da usabilidade de diferentes artefatos, que nos dias atuais parecem não ser de grande importância, mas que para este povo era a solução para muitos problemas.
Figura 02: Sra. Maria Sutili Lima com o pilão.

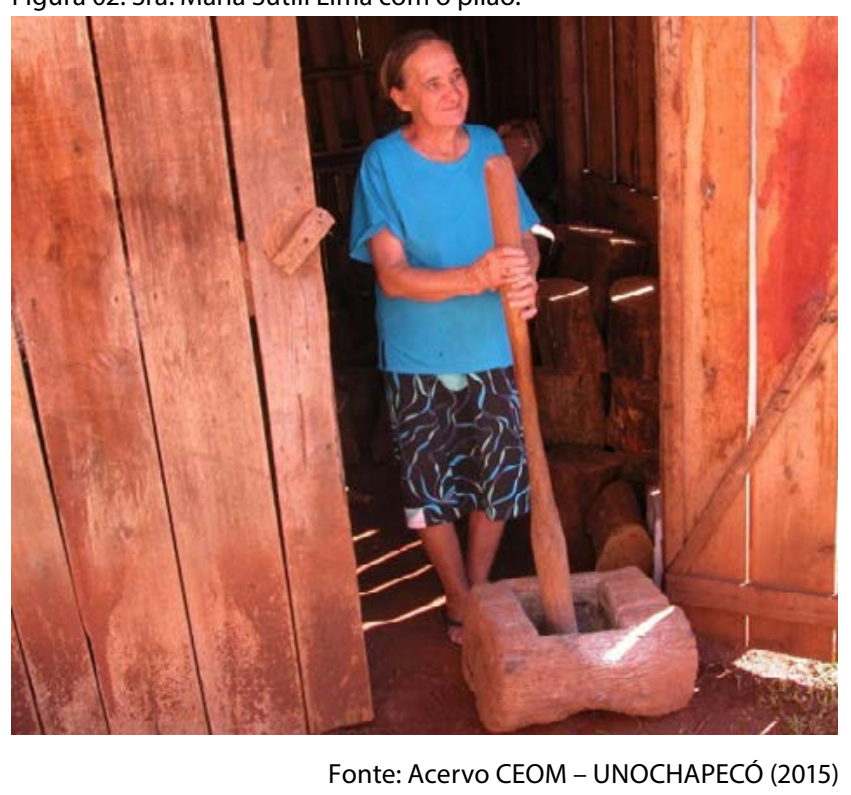

Sobre o valor dos produtos locais:

Das ações para valorizar os produtos locais, de acordo com (KRUCKEN, 2009 apud LORENZI, MORGENSTERN, CIPINIUK, 2015, p. 30), não existe uma receita única para elaborar projetos de valorização comercial ou de troca de produtos locais. Mas podem-se enumerar oito ações essenciais para promover os produtos e os território, favorecendo uma relação transparente e duradoura de produtores e consumidores: reconhecer as qualidades do produto e do território; ativar as competências situadas no território; comunicar o produto e o território; proteger a identidade local e o patrimônio material e imaterial; apoiar a produção local; promover sistemas de produção e de consumo sustentáveis; desenvolver novos produtos e serviços que respeitem a vocação e valorizem o território; e consolidar redes no território.

A visão de inovação quando ligada a um projeto de produto direcionando a um determinado público-alvo, busca conhecer e aprofunda a história das pessoas que ali vivem, baseando-se no modelo de vida desses indivíduos, como eles se comportam e quais suas necessidades diárias. A valorização de produtos locais, pode iniciar no momento em que se busca retratar as principais características, de modo a transpassar diferentes sensações aos usuários, resgatando sentimentos e sensações já vividas por meio destes produtos. 


\section{CULTURA CABOCLA}

Caboclos podem ser considerados como pessoas que possuem a visão sobre a simplicidade de viver. "Na medida em que a colonização chegava, o caboclo ia internando-se cada vez mais, formando o que antes definiu-se como a "frente da frente" de colonização, em busca de um local onde pudesse viver em paz." (POLI, 1995 apud Cadernos do CEOM, p. 98).

Segundo Fávero e Matiello (1998, p. 19) "A partir da lei das terras, 1850, a questão da terra para o caboclo se complicou. Na época da colonização, muitos compraram uma área de terra que também foi vendida para outra pessoa". Os caboclos preocupam-se com o hoje, trabalham suas pequenas lavouras e criam seus animais para o consumo próprio, não preocupam-se com o amanhã e com a ideia de acumular riqueza, pois tudo o que precisam está ao seu redor, os amigos, a "mão amiga dos vizinhos", a solidariedade é um dos pontos fortes do caboclo. "Os caboclos tiveram costumes baseados na sua relação com a natureza. Plantavam mandioca e alguma roça de milho, apenas para sua subsistência. Viviam mais da pesca e caça, por isto é que preferiam as margens dos rios para morar". (FÁVERO, MATIELLO, 1998, p.13).

Sobre a chegada dos caboclos na região oeste de Santa Catarina:

Os ancestrais caboclos, os troncos velhos, para cá vieram oriundos de diversos pontos do país. Alguns, os da Colônia Militar de Xapecó, instalada no atual município de Xanxerê, eram procedentes de estados do Nordeste, os chamados nacionais, e aqui permaneceram. Outros têm ancestrais indígenas, seja Kaigang ou Guarani. Uma parte descendente de escravos ou ex-escravos. Uns são egressos das fazendas de criar de Palmas, Lages ou do Rio Grande do Sul. Houve quem se embrenhasse nas matas coIhendo erva-mate e fazendo pequenas roças. Fizeram-se presentes combatentes e ex-combatentes da Revolução Federalista. Há aqueles que buscaram terra depois da expulsão pelas colonizadoras do Rio Grande do Sul. (RENK; SAVOLDI, 2008 apud Coleção Série Documento do CEOM, p. 13).

"Vivendo a margem da sociedade, donos de uma vida simples, o trabalho braçal é uma das principais características deste povo." (FAVARETTO, 2015, p. 13). Trabalhar a roça cabocla, a lida com os animais e principalmente seu papel na extração da madeira e da erva-mate, podem caracterizar o modo de vida cabocla.

O caboclo sempre teve sua vida à margem de sociedade, servindo de mão-de-obra a fazendeiros, ervateiros e madeireiros. Embora representassem a maioria da população, os caboclos sempre foram despossuídos. Raramente conseguiam obter a propriedade de uma pequena área de terra, para se manterem com suas pequenas roças caboclas. (POLI, 2006, p. 174).

Sobre a ocupação das terras na região do Oeste Catarinense:
Na região Oeste, no início do século, havia a "terra de ninguém", "terra devoluta", ocupada por pequeno número de habitantes que não possuíam a propriedade da terra que explora- vam. Poucas áreas tinham proprietários e nem mesmo as grandes colonizadoras haviam to- mado posse das terras. A região toda constituía o chamado "Velho Chapecó", Da área original- mente formada do território chapecoense, em diferentes épocas, foram desmembrados em mais de 60 municípios, incluindo o próprio mu- nicípio de Chapecó. (POLI, 1995 apud Cadernos do CEOM, p. 74).

"A população que sucedeu à indígena e miscigenou-se com esta foi a dos luso-brasileiros." (POLI, 1995 apud Cadernos do CEOM, p. 73). Os luso-brasileiros, como também são chamados os caboclos, desenvolveram no oeste catarinense seu modo de viver.

A cultura cabocla esteve presente em diversas cidades da região Oeste de Santa Catarina, uma cultura que permanece viva até os dias atuais. Marcada pela simplicidade nas formas de viver e agir, coração puro, destinados a ajudar os necessitados, os mutirões para trabalhos braçais eram umas das características que reforçam esta cultura, ajudar os que precisam para que na necessidade se consiga ajuda também. A cultura cabocla se destaca por suas particularidades e tradições que passam de geração para geração caracterizando a cultura imaterial desta região. (FAVARETTO, 2015, p. 13).

Na Figura 03 pode ser visualizado como eram as "moradas" caboclas. 
Figura 03: Casa em Faxinal dos Guedes-SC, na década de 1940.

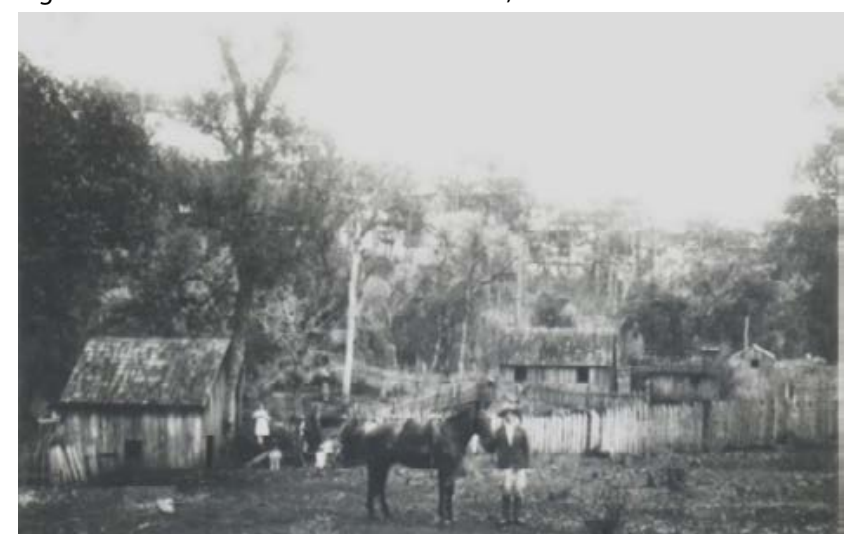

Fonte: Acervo CEOM - UNOCHAPECÓ (2015).

“Não há uma fenotípica única que possa caracterizar o caboclo. É uma etnia que partilha valores comuns, como a solidariedade, o destemor, a religiosidade popular, a honra, valores em relação ao tempo, sem preocupação em acumular; fazer para viver e saber viver hoje." (RENK; SAVOLDI, 2008 apud Coleção Série Documento do CEOM, p. 13). Trabalhar a roça e colher as riquezas produzidas caracteriza a felicidade dessas pessoas.

Onde os caboclos que conseguiram alguma forma de enriquecimento passaram a denominar-se portugueses ou brasileiros e não mais admitam a denominação de caboclos. Alguns filhos de caboclo que tiveram acesso à instrução e que conseguiram completar estudos de mais alto grau também deixaram de denominar-se dessa forma. Basicamente o caboclo é conceituado como Luso-brasileiro e sua condição fundamental de reconhecimento é ser pobre e viver toscamente. (POLI, 2006, p. 176).

Segundo Fávero e Matiello (1998, p.14) “O caboclo hoje sente-se vencido, sem força de lutar. Foi a própria sociedade que contribuiu para que se sentisse desta forma. A partir do momento que lhe é negado viver sua própria cultura, é tirada sua identidade." Vivendo como subalternos o caboclo passou a desempenhar o papel de empregado, servindo aos colonizadores donos das terras.

\section{ARTEFATO DA CULTURA CABOCLA - FACÃO DE PAU}

Por meio de visita ao Museu Histórico e Antropológico da Região do Contestado, localizado na cidade de Caçador - SC, realizada no dia 28 de Setembro de 2016 foi possível coletar informações e fotos sobre o facão de pau, artefato desenvolvido artesanalmente e muito utilizado pelo caboclo da região Oeste de Santa Catarina. Acreditase que o facão de pau era utilizado pelos caboclos na luta diária do campo, em seu trabalho na terra, no corte da erva mate e possivelmente nas lutas corpo a corpo com os soldados na guerra do contestado e demais confrontos. $O$ facão de pau pode ser considerado um artefato representativo da cultura dessas pessoas que foram despossuídas de suas terras e passaram a servir de mão de obra aos colonizadores que chegaram e foram tornando os caboclos subalternos. Durante um ano e meio de estudos referente a cultura cabocla, muito se ouviu falar a respeito das habilidades do caboclo com o facão de pau e de seu jeito "simples" de viver, sem se importar com o luxo e o acumulo de riqueza.

Ao longo das pesquisas e entrevistas realizadas, um dos assunto que chamou bastante atenção foi a utilização do facão de pau pelo caboclo, um artefato que acarretou diversas dúvidas a respeito de sua fabricação e utilização, a partir daí buscou-se aprofundar as pesquisas neste artefato tão caraterístico dessas pessoas.Na visita ao Museu do Contestado, novas informações foram coletadas a respeito do uso do facão pelo caboclo.

Na figura 04 pode ser visualizado o facão de pau, artefato pertencente ao acervo do museu do Contestado em Caçador - SC.

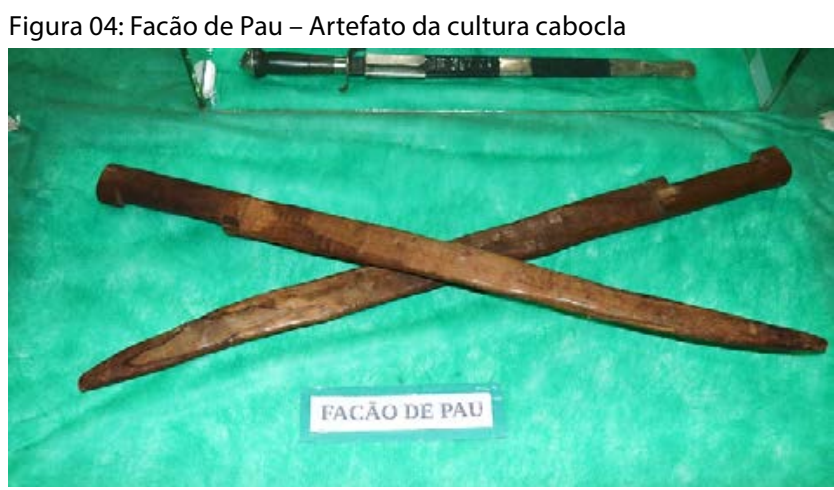

Fonte: Elaborado pelo autor (2016)

\section{ANÁLISE DO FACÃO DE PAU}

A lógica de fabricação do facão de pau pelos caboclos, pode ter sido pelo uso do formão, ferramenta utilizada para talhar a madeira e dar forma ao facão. O caboclo utilizava o facão diariamente, o que caracteriza sua forte habilidade e o receio dos soldados nos confrontos, onde os caboclos faziam "tocaias" para atacar os inimigos de forma mortal, cercando-os e encurralando-os. O facão possui uma forma mais arredondada, imagina-se então sua utilização para perfurar o inimigo, acredita-se que 
a madeira utilizada na produção do facão de pau era a madeira falquejada e as mais usadas eram Guaramirim, Pessegueiro Bravo e Araçá, por possuírem fibras mais resistentes evitando que lascassem ou quebrassem. Devido ao seu grande conhecimento das matas, os caboclos possuíam a habilidade de aperfeiçoar técnicas de combate e artefatos com maior aperfeiçoamento que os demais.

Nas figuras 05, 06, 07 e 08 é possível visualizar detalhes do facão de pau artefato pertencente ao acervo do museu do Contestado em Caçador - SC.

Figura 05: Fotos de detalhes do facão de pau. Artefato da cultura cabocla

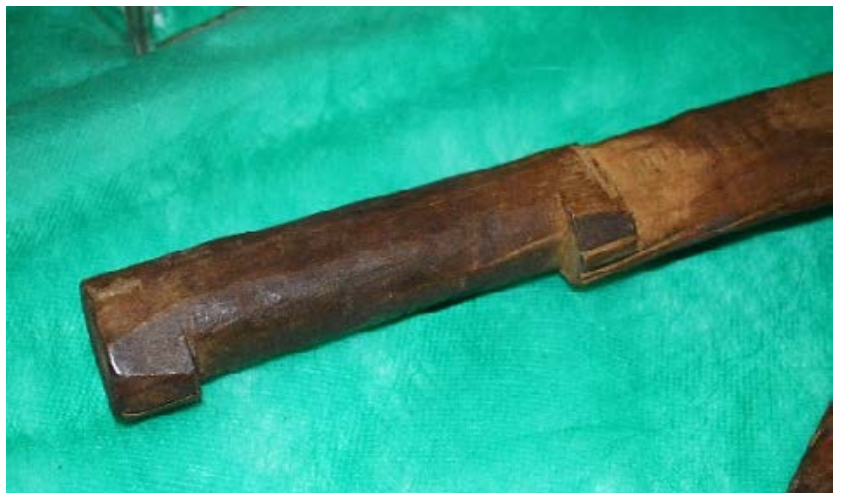

Fonte: Elaborado pelo autor (2016)

Figura 06: Fotos de detalhes do facão de pau. Artefato da cultura cabocla

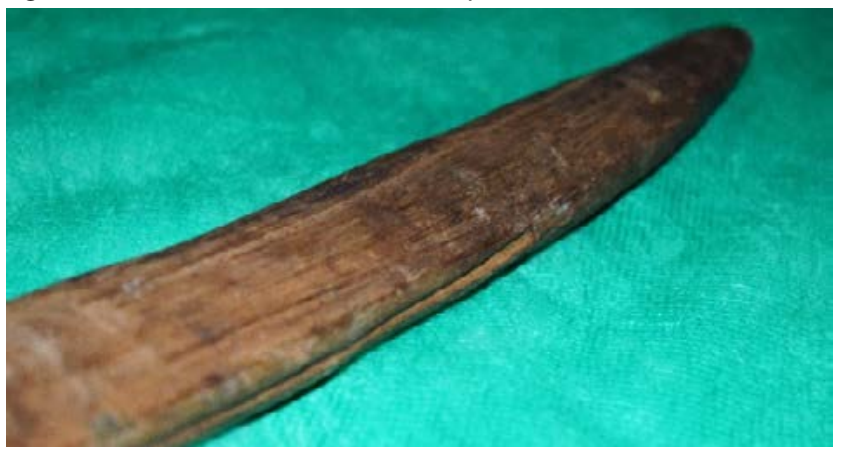

Fonte: Elaborado pelo autor (2016)

Figura 07: Fotos de detalhes do facão de pau. Artefato da cultura cabocla

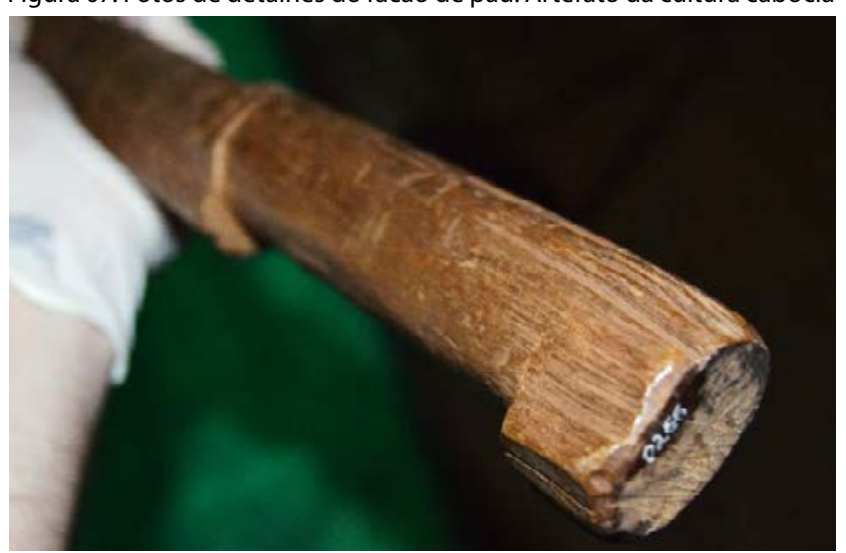

Fonte: Elaborado pelo autor (2016)
Figura 08: Fotos de detalhes do facão de pau. Artefato da cultura cabocla

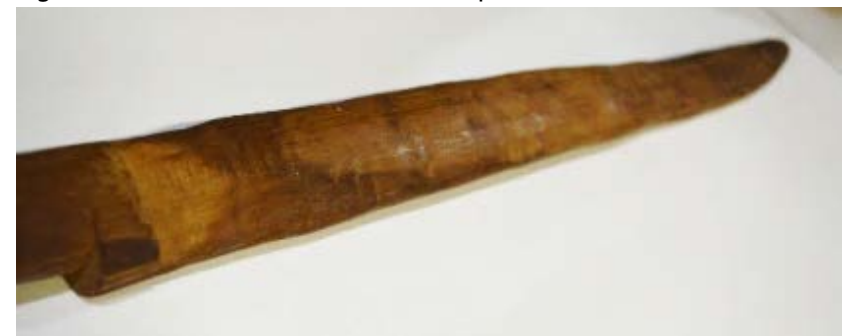

Fonte: Elaborado pelo autor (2016)

No Quadro 01 pode-se visualizar a análise de artefato caboclo, levando em consideração aspectos como Artefato, Década, Tarefa executada, Usuário, Ambiente de trabalho, material e peso.

Quadro 01: Análise de artefato caboclo: Artefato, Década, Tarefa executada, Usuário, Ambiente de trabalho, material e peso.

\begin{tabular}{|r|l|}
\hline Artefato & Facão de Pau \\
\hline Década & Entre 1910 e 1916 \\
\hline Tarefa executada & $\begin{array}{l}\text { Corte de erva mate. } \\
\text { Corte de mato em geral, } \\
\text { lida no campo. Degola } \\
\text { em confrontos, luta na } \\
\text { Guerra do Contestado. }\end{array}$ \\
\hline Usuário & Caboclo \\
\hline Material & $\begin{array}{l}\text { Roça, campo. Guerra do } \\
\text { Contestado. } \\
\text { Madeiras Guaramirim, } \\
\text { Pessegueiro Bravo, } \\
\text { Araçá. }\end{array}$ \\
\hline Peso trabalho & 450g \\
\hline
\end{tabular}

Fonte: Elaborado pelo autor (2016)

\section{PROJETO DE PRODUTO: RESGATE DA IDENTIDADE CULTURAL}

A partir da ideia de desenvolver um produto de design que contenha a identidade da cultura material do caboclo da região oeste de Santa Catarina, pensou-se em realizar o projeto de um produto aplicando funções como a simbólica, a fim de transmitir ao usuário final diferentes sensações e um pouco da história dessas pessoas. A partir dos estudos realizados ao longo desta pesquisa, um dos artefatos utilizados pelo caboclo que mais esteve presente nos diálogos e discursos dos historiadores pesquisados foi o facão de pau.

As sociedades contemporâneas estão interconectadas de várias formas, uma delas se dá através dos meios de comunicação. Mas mais do que isto e talvez uma coisa menos enfatizada, é 
que as sociedades contemporâneas, não todas, é claro, mas grande parte delas, participam de uma mesma matriz. Essa matriz emergiu com a modernidade. Tem a ver com a ciência, a tecnologia, a urbanização, a industrialização a ponto de elementos desta matriz serem encontrados fora dos seus lugares. (ORTIZ, 2000, p 68).

No campo de design quando se fala em design contemporâneo, vale a pena buscar incorporar o resgate cultural como forma de inovar e diferenciar novos produtos que serão apresentados ao mercado. Assim, buscou-se reproduzir uma estética simbólica fiel de um projeto de produto de um facão de pau, pensando nas possibilidades de produção em escala, o qual pode ser utilizado como mostruário em museus da região e especialmente funcionaria com um material didático, podendo ser utilizados por professores no ambiente de ensino e aprendizagem escolar, possibilitando aos alunos um artefato tocável, que transmita a história do caboclo, essas pessoas simples e trabalhadoras constituintes da história da região oeste de Santa Catarina.

Vale ressaltar que o facão de pau é um objeto que pode ser utilizado para atacar ou se defender de alguém ou de alguma coisa, caracterizando-o como uma arma branca, embora não tenha essa finalidade no referente projeto.

\section{PROJETO DE PRODUTO: CABOCLO DESIGN RÚSTICO}

A partir do resgate da identidade cultura do caboclo, a fim de realizar o projeto de um produto de design com diferencial, buscou-se de forma artesanal talhar um protótipo de facão de pau, utilizando a mesma matéria prima do facão utilizado pelos caboclos, a madeira. Desta forma pode-se ter a oportunidade de trabalhar a madeira, sentindo cada prazer de desenvolver um produto artesanal talhado manualmente e focado no resgate cultural, o qual transmite as diferentes sensações vividas pelo caboclo.

Dentre vários artigos estudados não encontrou-se nenhuma metodologia específica para análise cultural social especificadamente do Design. Desta forma, optou-se por trabalhar um método clássico e simples baseado na metodologia de Bruno Munari.

\section{MÉTODO DE CRIAÇÃO: ADAPTAÇÃO DA METODOLOGIA DE BRUNO MUNARI}

Problema: Manter uma estética simbólica.

Definição do problema: Valorização da estética simbólica como instrumento didático pedagógico.
Componentes do problema: Resgate cultural, fator simbólico, artesanato, rusticidade.

Análise de dados: No quadro 02 é possível visualizar uma análise sobre os aspectos simbólicos do Facão de Pau, levando em consideração aspectos como Contexto Histórico, Material Aplicado, Função e Referências Visuais (Cor, Forma, Textura).

Quadro 02: Análise de artefato caboclo: Artefato, Década, Tarefa executada, Usuário, Ambiente de trabalho, material e peso.

\begin{tabular}{|c|c|}
\hline Contexto Histórico & $\begin{array}{l}\text { Acredita-se que sua } \\
\text { utilização se dá por volta } \\
\text { dos anos } 1910 \text { na lida do } \\
\text { dia a dia, no cuidado da } \\
\text { roça, no corte da erva- } \\
\text { mate e em confrontos } \\
\text { comona Guerra do } \\
\text { Contestado. }\end{array}$ \\
\hline Material Aplicado & $\begin{array}{l}\text { Acredita-se que o } \\
\text { material utilizado no } \\
\text { entalhe dofacão de pau } \\
\text { eram madeiras como: } \\
\text { Guaramirim, Pessegueiro } \\
\text { Bravo e Araçá. Possível } \\
\text { utilização de sebo de } \\
\text { ovelha para dar brilho e } \\
\text { proteger a madeira, } \\
\text { criando uma camada } \\
\text { impermeável. }\end{array}$ \\
\hline Função & $\begin{array}{l}\text { Cortar, perfurar. Muito } \\
\text { utilizado como arma de } \\
\text { combate. }\end{array}$ \\
\hline \multirow[t]{3}{*}{ Referências Visuais } & $\begin{array}{l}\text { Cor: Madeira natural, sem } \\
\text { cobertura de tinta, } \\
\text { possível aplicação de } \\
\text { verniz ou sebo de ovelha. }\end{array}$ \\
\hline & $\begin{array}{l}\text { Forma: A forma do facão } \\
\text { de Pau é dada pelo } \\
\text { entalhe na madeira. } \\
\text { Medindo cerca de } 70 \mathrm{~cm} \\
\text { de comprimento. }\end{array}$ \\
\hline & $\begin{array}{l}\text { Textura: Madeira } \\
\text { entalhada, rustico, } \\
\text { desgastado. }\end{array}$ \\
\hline
\end{tabular}

Fonte: Elaborado pelo autor (2016)

Criatividade - Geração de alternativas: O objetivo principal da pesquisa não foi criar uma marca, foi de manter e criar uma estética simbólica que tivesse um artefato em especial, que representasse a máxima do 
significado do que é ser caboclo na região oeste de Santa Catarina.

Na Figura 09 é possível visualizar a geração de alternativas de uma marca que representasse a estética simbólica do caboclo.

Figura 09: Geração de alternativas de marca com estética simbólica do caboclo do oeste de Santa Catarina

\section{$\frac{C A B O C L O}{\text { Design Rústico }} \underset{\text { Design Rustico }}{\mathrm{CABOCLO}} \frac{\mathrm{CABOCLO}}{\text { Oesign Rustico }}$}

Fonte: Elaborado pelo autor (2016)

Nas figuras 10 e 11 é possível visualizar o estudo do facão de pau no Museu Histórico e Antropológico da Região do Contestado, localizado na cidade de Caçador - SC.

Figura 10: Estudo das dimensões do facão de pau.

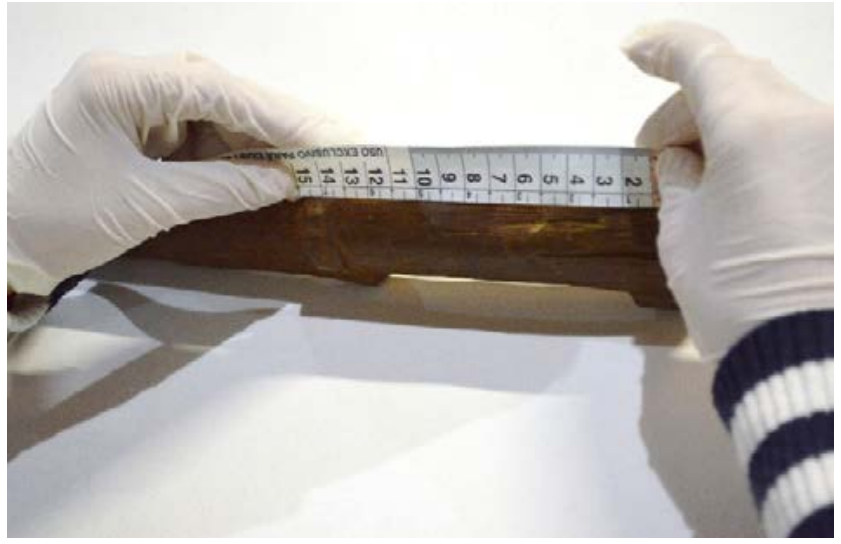

Fonte: Elaborado pelo autor (2016)

Figura 11: Estudo das dimensões do facão de pau.

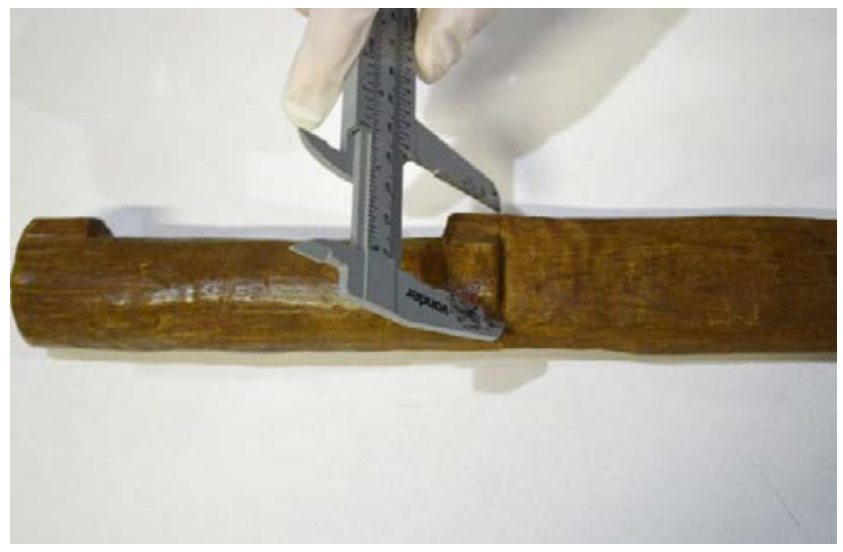

Fonte: O autor (2016).

Experimentação: Nas Figuras 12 e 13 é possível visualizar detalhes do processo de produção de um protótipo de facão de pau talhado a mão.
Figura 12: Detalhes do processo de produção do protótipo de facão de pau

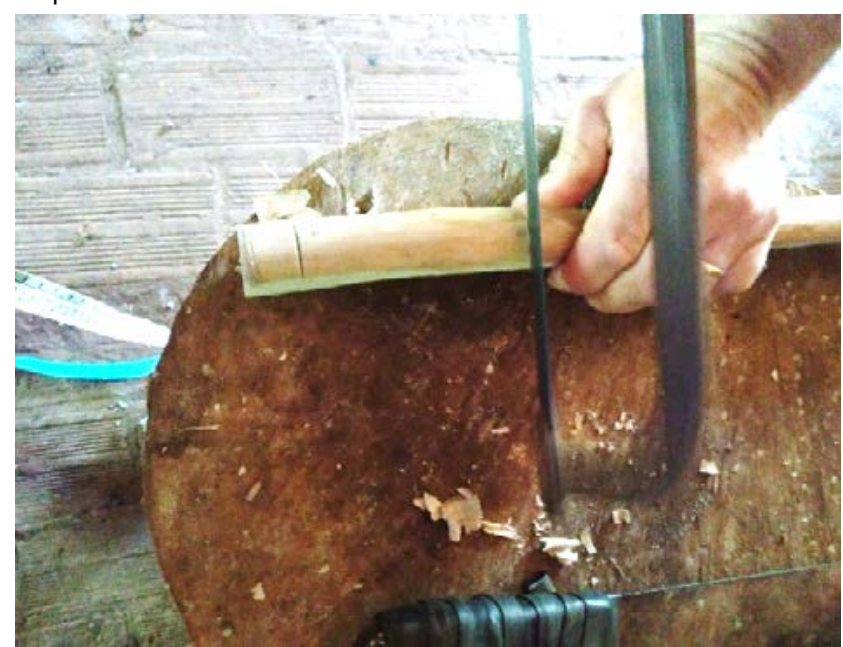

Fonte: Elaborado pelo autor (2016)

Figura 13: Detalhes do processo de produção do protótipo de facão de pau

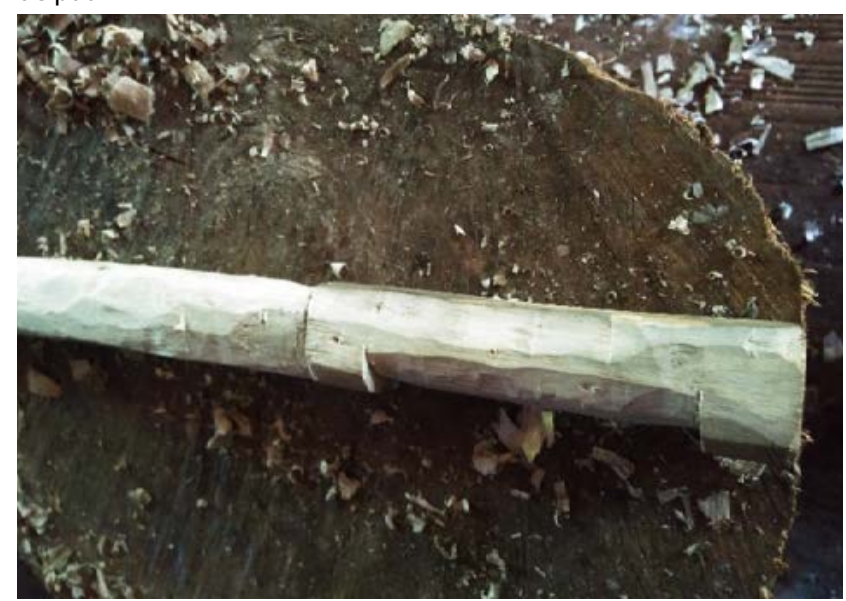

Fonte: Elaborado pelo autor (2016)

Solução: Nas figuras 14, 15 e 16 é possível visualizar a marca final, escolhida para representar a máxima do significado do que é ser caboclo na região oeste de Santa Catarina, o protótipo do facão de pau talhado de forma artesanal e a dimensão do facão de pau em relação ao usuário.

Figura 14: Marca final - Caboclo Design Rústico

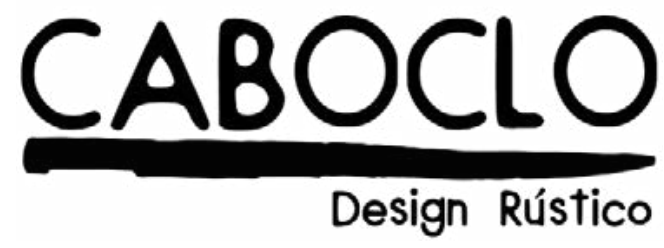

Fonte: Elaborado pelo autor (2016) 
Figura 15: Detalhes do protótipo de facão de pau talhado artesanalmente

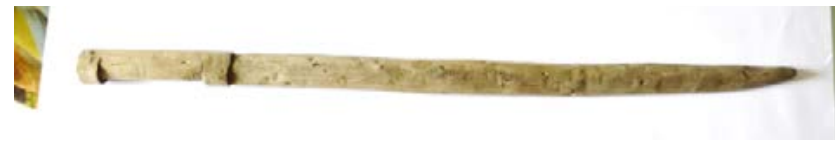

Fonte: Elaborado pelo autor (2016)

Figura 16: Dimensão do protótipo de facão de pau em relação ao usuário

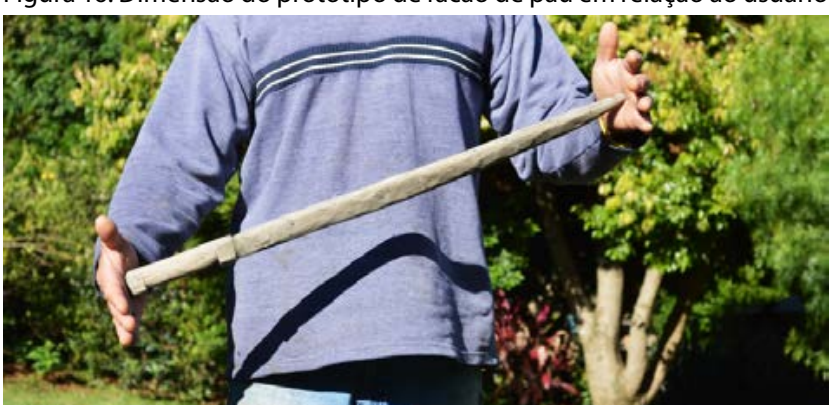

Fonte: Elaborado pelo autor (2016)

\section{CONCLUSÕES}

Por meio da realização de pesquisas, nas quais resgatou-se ao longo de um ano e meio a história do caboclo da região oeste de Santa Catarina, buscou-se compreender questões como cultura, costumes, crenças, seu modo de vida, quem eram essas pessoas e os artefatos por elas utilizados, a fim de relaciona-los com o design.

Apartir destes resgates históricos estudados pelo viés do design e das pesquisas realizadas referentes aos artefatos utilizados pelos caboclos, a fim de facilidar seu dia a dia, no trabalho da roça e na luta da erva, por exemplo, buscou-se neste artigo projetar a reprodução fiel de um produto de design de fator simbólico, levando em consideração os estudos realizados até o presente momento.

Este artigo faz parte de uma linha de pesquisa, a qual busca estudar o caboclo da região oeste de Santa Catarina pelo olhar do design. Ao longo de três semestres de estudo, buscou-se desenvolver uma pesquisa sobre o resgate histórico do caboclo, como forma de contribuir com o resgate histórico cultural de uma determinada região. A região oeste de Santa Catarina conta com inúmeros museus espalhado por toda região, nos quais buscou-se realizar as pesquisas que contribuíram para o desenvolvimento desta linha de estudo, onde buscou-se aplicar os conhecimentos teórico-metodológicos de um designer, caracterizando a importância do design como contribuinte deste resgate histórico, trabalhando no projeto de novos produtos de design que mantenham viva a história e a identidade de uma cultura, neste caso a cabocla.

Ao longo de toda pesquisa foram coletados dados a respeito do modo de vida do caboclo desde o período da colonização da região oeste de Santa Catarina. Estudar e compreender sobre o modo de vida dos caboclos possibilitou projetar a reprodução do facão de pau utilizado por essas pessoas, mantendo características como cor, forma e textura, a fim de aplicar a função simbólica, para que este produto transmita aos usuários um pouco da história dessas pessoas.

A ideia desta marca, Caboclo Design Rústico, acompanhará a continuação do estudo, que tem uma missão essencial: contribuir no processo de manter o valor simbólico desta cultura regional e por meio do projeto desenvolvido no presente artigo disseminar e futuramente galgar propostas de materiais didáticos para escolas de ensino básico e fundamental e ou museus da Região Oeste de Santa Catarina, não com a intenção de apropriação, mas sim de compartilhar histórias que dão o verdadeiro valor da simplicidade, riqueza e a beleza da cultura cabocla do Oeste de Santa Catarina.

\section{AGRADECIMENTOS}

Agradecimento especial à toda equipe do Museu Histórico e Antropológico da Região do Contestado, localizado na cidade de Caçador, Santa Catarina.

\section{REFERÊNCIAS}

BONSIEPE, G. Do material ao digital. São Paulo: Blucher, 2015.

BÜRDEK, B. E. Design: História, teoria e prática do design de produtos. São Paulo: Blucher, 2010.

BAXTER, M. Projeto de produto: guia prático para o design de novos produtos. São Paulo: Edgar Blücher, 1998.

CARDOSO, R. D. Uma introdução a história do design. São Paulo: Editora Edgard Blücher LTDA, 2000.

CARPES JR, W. P. Introdução ao projeto de produto. Porto Alegre: Bookman, 2014.

FAVARETTO, A. J. A importância das funções de produto como mantenedora da cultura cabocla da região oeste de Santa Catarina. Chapecó, 2015.

FÁVERO, I.; MATIELLO, J. A. Um conflito interétnico: Caboclos e italiano em Coronel Freitas. Chapecó, 1998.

LIPOVETSKY, G. 0 império do efêmero: A moda e seus destinos nas sociedades modernas. São Paulo: Editora Schwarcz LTDA, 2002. 
LORENZI, R. C. R.; MORGENSTERN, E.; CIPINUK, A. Design e artesanato: $O$ valor simbólico dos produtos artesanais no campo da moda. Joinville, SC: Editora Univille, 2015.

LÖBACH, B. Design industrial: Bases para a configuração dos produtos industriais. São Paulo: Editora Edgar Blücher LTDA, 2001.

MUNARI, B. Das coisas nascem coisas. São Paulo: Martins Fontes, 1998.

NIEMEYER, L. Elementos de semiótica aplicados ao design. Rio de Janeiro: 2AB, 2007.

ONGHERO, A. L. Retratos e memórias da história de formosa do sul. Chapecó: CEOM/Unochapecó, 2012.

ORTIZ, R. Comunicação \& Educação: Identidades culturais no contexto da globalização. São Paulo, 2000.

POLI, J. Para uma história do Oeste Catarinense. 10 anos de CEOM.Cadernos do CEOM. Chapecó: UNOESC, 1995.

POLI, J. Cadernos do CEOM. Chapecó: Argos, 2006.

RENK, A.; SAVOLDI, A. Centro de memória do oeste de Santa Catarina. Inventário da cultura imaterial cabocla no oeste de Santa Catarina. Coleção Série Documento do CEOM. Chapecó: Argos, 2008. 